8

\title{
The collaborative engineering process within the framework of the virtual enterprise
}

M. Williamson, MBA, PMP

Project Solutions

Seattle, WA 98107-4039, USA

email:matt@projectsol.com

Dr. R. L. Storch, Ph.D., P. E.

Industrial Engineering, University of Washington

Seattle, WA 98195-2650 USA

email: rlstorch@u.washington.edu

\begin{abstract}
The virtual enterprise has become a prominent organizational structure under which small and medium sized enterprises having strong, narrowly focused core competencies can band together to accomplish large projects. Great strides have been made in the evolution of the virtual enterprise as a collaborative engineering environment; however, in many cases, a key component of the virtual enterprise is missing that allows for the enterprise to stay focused on project goals, rather than concentrate on conflict resolution among its members. This component is the project manager. By having a project manager take responsibility for the management of the project, the virtual enterprise can maintain its collaborative environment and its members can remain focused on the goals of the project.
\end{abstract}

\section{Keywords}

Virtual Enterprise, Collaborative Engineering, Project Management, US Marine Industry 


\section{INTRODUCTION}

Recent articles in the popular press, as well as many professional journals, have pointed to the virtual enterprise as the newest model of the successful organization. (Caskey, 1995) In defining the virtual enterprise, many iterations have been developed and discussed. Typically a virtual enterprise takes shape in an intrapreneurial project team in a large organization. Another common form of the virtual enterprise is that of a large corporation outsourcing a specific need to or utilizing particular resources of a smaller consulting firm.

The first of these models is derived from the need of a large enterprise to accomplish a multi-disciplined project. Representatives from the necessary functional departments of the organization are brought together to form a project team. Often the project team members are co-located and can concurrently complete their functional tasks.

The second of these models is derived from the need of a larger corporation to outsource a product or service required for the operation of that corporation. The larger corporation, while needing the service, has made the strategic decision that providing the service internally is no longer within its core competencies. The smaller company has been established to provide the service and has formed its business around the core competence required to deliver that service.

A model not mentioned above is that of the extended enterprise. While not much literature has been developed regarding this model, it is a model that is viable and indeed the most agile form of the virtual enterprise. It consists of small and medium-sized enterprises (SME), where each have developed a limited, yet strong and unique, set of core competencies. These enterprises can bring their strengths together using Internet-based communications technologies to collaboratively engage in a project to develop and produce a complete product. An advantage of this organizational structure is that each SME can maintain a diverse customer base, where consultants providing a single service as described above must cater to a single, or similar set of clients. While the extended enterprise is arguably the most agile of the virtual organization models, it comes with some additional risks which do not exist in the others.

The US marine industry has begun to acknowledge this model as a viable business process. This paper discusses the structure of this model in a segment of the US marine industry and presents a brief description of the technology required for successful implementation. Also, on a level applicable over a broad range of industries, the differences between concurrent engineering processes and collaborative product development are defined. Finally, through a description of a case study, project risks are evaluated and methodologies for their mitigation among project partners suggested. 


\section{THE EMERGENCE OF THE EXTENDED ENTERPRISE MODEL}

At the height of the Industrial Revolution in the United States, the scarcest resource was the capital required to buy facilities, equipment and raw materials. Economies of scale were the predominate concepts of the time. Concentration on mass production tended to diminish the role of the individual worker in the process, in that he served as the control mechanism used to determine if a process could be automated. Development and engineering processes were not considered to be on the critical path of the product life cycle. As long as the manufacturing processes were efficient and large quantities of a product could be sold, the retention of functional engineering and serial product design processes were considered to be state-of-the-art.

However, as technology has developed and the infrastructure of nations, as well as individual companies, has improved, competition for market share has become predicated on the improvement of all activities involved in doing business. Companies are learning that they can no longer depend solely on equipment and facilities, but need to improve their knowledge based infrastructure, such as engineering and product development, as well.

This represents a significant shift from a monetary based capital perspective to a knowledge based capital perspective; a perspective from which companies can clearly see the value in returning to and strengthening their core competencies. It also represents a shift in basic economics. Rather than the continued development of regional economies based on allocation of scarce resources, knowledge capital allows for the development of a global economy based on the unlimited combination of these resources.

The economics of ideas is a thesis put forth by Paul Romer (Kelly, 1996). According to Romer, the world should no longer be defined by scarcity and limits on growth. Instead it should be thought of as a playground of nearly unbounded opportunity, where new ideas beget new products, new markets and new possibilities to create wealth. The shift in thinking from traditional economic theory comes from dividing the world into physical objects and ideas, rather than wants and physical objects. If physical ideas are scarce, then the only decision left for traditionalists is how to allocate those scarce resources to maximize wealth. By coming up with new ideas that reconfigure the interaction between resources, humans can boost productivity, spawn new profit opportunities and ultimately drive economic growth.

To draw the business analogy with this concept, as the potential development of products is based on the combinations of resources, the form of the enterprises necessary to configure those resources into new products and services is based on the combination of available knowledge and skills. This combination of knowledge and skills is the foundation of the extended enterprise. In conjunction with the development of knowledge capital, SMEs are shedding product and service offerings that do not bolster the core competencies of the business and are strengthening those that do. As a part of this development, SMEs must make 
crucial decisions about what specifically represents a core competency that can be fully utilized and continuously improved. Other organizational capabilities must be shed in order to maximize the benefits obtained from the core competencies, while minimizing the expense and need to improve other activities. As a result of this trend, SMEs are increasing in number, and the strength of these SMEs is potentially greater. This increasing pool of narrowly focused, highly skilled small enterprises, allows for those within that pool to selectively combine forces to achieve two strategic ends.

First, in partnering with other similar sized organizations, smaller firms can achieve the strength of large corporations, yet stay focused on the project for which they are competing and reduce the overhead associated with maintaining capabilities in a wide range of areas, as is common in large corporations. Second, these organizations, in working in a collaborative environment, can reduce the time required to develop and produce products and services. The latter of these is the focus of the remainder of this paper.

\section{CONCURRENT VERSUS COLLABORATIVE ENGINEERING}

The fundamental difference between the classical definition of concurrent engineering and what the authors and others are defining as collaborative engineering is the communication process. Communication is mediated in the concurrent engineering process. In the collaborative engineering environment, communication is the process enabler.

Concurrent engineering is an engineering process that came into large favor in the late 1980's. It has been a process that has been effective in substantially reducing product development times. The basic philosophy of concurrent engineering is to develop the different aspects of product specification in parallel processes instead of a number of sequential phases (Pels, 1995). In theory this is completely a parallel process; however, in practice the result is often a series of sequential processes running in parallel.

During the concurrent engineering process, cross-functional teams are often formed. In a matrix organization, these teams are loosely controlled by the project manager, but the members may still be required to report to their functional managers. Consequently, the functional processes required for product definition remain intact. To enable a concurrent process, parallel levels of detail for each function are defined, and the team members produce only to the required level of detail before passing on the product to the functional organization. This process cycles until the desired product quality is achieved. In this process, the overall development time is reduced because the functional groups work in parallel, but collaboration between team members only occurs during team meetings when interim products are passed to the next functional organization.

This definition of concurrent engineering has been the norm for an organization which is geographically dispersed. To overcome the problems associated with this 
communication process and place the engineering team in a more collaborative environment, a common solution has been to co-locate team members in a single room. In this case, communication is readily enabled due to the close proximity of the project team; this is the model for the collaborative engineering process.

Since each team member has ready access to other team members and the portions of the product for which they are not responsible, a collaborative problem solving environment is created. In this environment, product definition is enabled by communication and discrete iterations between levels of detail are blurred. As a result, cycle time is reduced from that of the concurrent engineering process because of the fact that contributions of the team functions can be made when necessary and the next function in the process does not have to wait for the completed level package from the previous.

Even recently, the idea of collaborative engineering among geographically disbursed team members considered to be far-fetched. It was perceived that communication was only effective in the environment where the team members were co-located (Pels, 1995). However technological changes have made the collaborative engineering process possible among several individual enterprises acting as a virtual organization.

In the United States, as improvements in technology have enable remote collaborative communication, many industries have easily adapted to the virtual enterprise organization structure. Currently, the marine industry, which is traditionally slow to adopt new technology, is beginning to accept the concept of the virtual enterprise, as well. This is evidenced by the surge in projects being sponsored by government and undertaken by corporate partnerships to deploy sophisticated communication process technologies into this industry, as well as smaller experiments undertaken by small and medium sizes enterprise cooperation.

\section{A MODEL OF THE VIRTUAL ENTERPRISE IN THE US MARINE INDUSTRY}

The virtual enterprise is a consortium of several business entities supporting a common goal. Because each partner brings a strength, or core competence to the consortium, the success of the project depends on all cooperating as a unit (Caskey, 1995). The US Marine industry is indeed ripe for doing business in such a collaborative, yet geographically dispersed environment.

The US marine industry is perhaps best known for its six largest shipyards; however, there is a wide range of enterprises, both in terms of size and industry segmentation. Recent data have shown that there are nearly 2500 shipbuilding, boatbuilding and ship repair firms in the United States. In support of these enterprises, there are naval architect and marine engineering firms, material suppliers, and regulatory bodies.

Currently, typical vessel design and build strategies are undergone in a sequential fashion, as shown in Figure 1. 


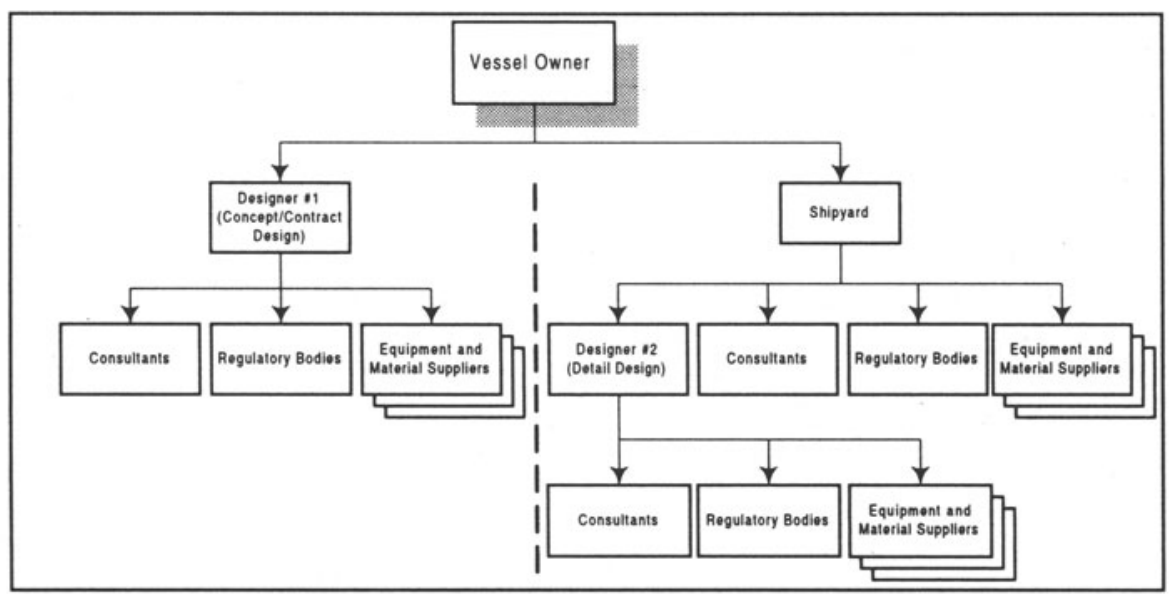

Figure 1 The Traditional Vessel Design/Build Organizational Structure

The designer creates the vessel design in the form of an electronic drawing database. During this drawing development process, computer-aided engineering and drafting (CAE and CAD) software packages are used. Often, because these packages may be incompatible, technical data cannot be electronically passed from one to the other. Worse yet, vendors may supply information to the designer which may be electronically incompatible or paper-based. Finally, via paper copies of the CAD developed drawings, the vessel design is communicated to the owner. Upon approval of the design, specifications are written which, along with the drawings, are sent to building contractors for bids. This is done without using the electronic media in which the specifications and drawings were developed. Further, the bidders may invite input from vendors not used by the owner/operator or the designer during the initial phase of this design process.

At the time of contract award, the building contractor uses the drawings and specifications to create working drawings, numerical controlled (NC) machine code, and work instructions specific to their capabilities. If the electronic data is compatible and he chooses to use the CAD drawing database, it is at his risk. If the information is not compatible, or the risk is considered to be unacceptable, then the lines are redrawn and the NC code is rewritten.

The above scenario forces inefficiency into the design process and causes unnecessarily high costs and long product development cycles. By doing business in this traditional sequence the vessel is designed twice, first by the owner and his designer agent, then by the builder. This paper suggests a model which allows for an innovative partnering arrangement through which these sequential steps are done in a virtual enterprise as a distributed collaboration, as shown in Figure 2. 


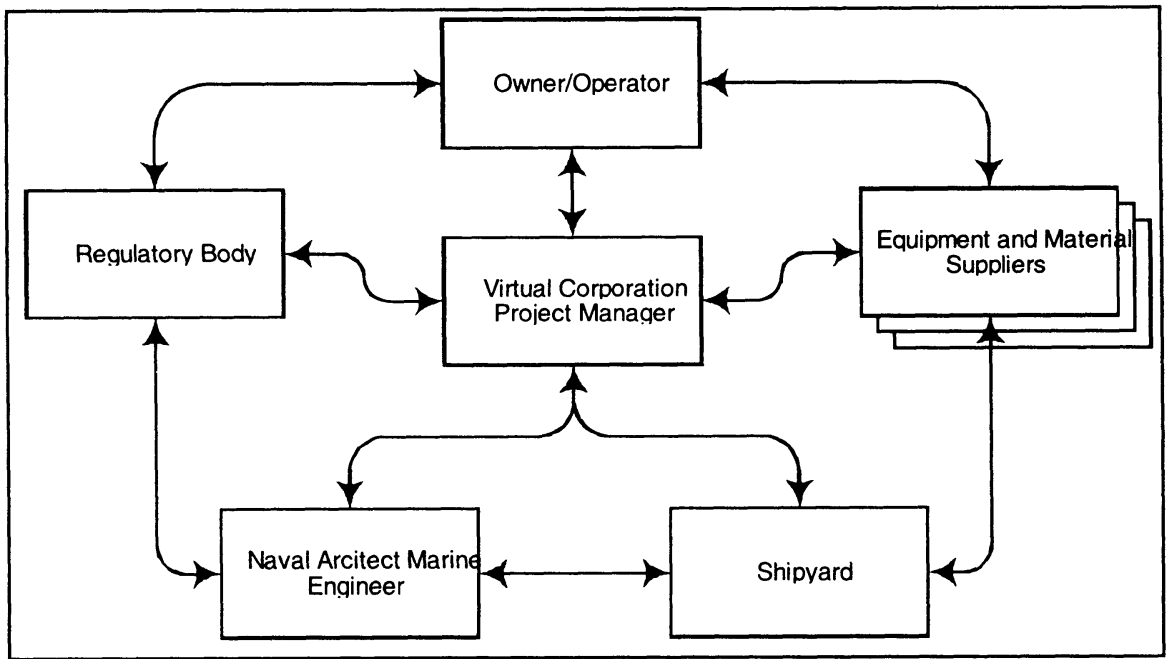

Figure 2 Virtual Collaborative Distributed Enterprise Organizational Structure

Figure 2 suggests a collaborative environment since each enterprise has access to the other. Introduced into this model is the project manager. Because ship design and construction is a complicated activity, the authors believe that the project manager is necessary in this model for this model of the virtual enterprise to succeed. The role of the project manger, discussed later in this paper, is to coordinate activities among the project partners required to reach project milestones -- not mediate communication. Another strength of this arrangement is that all project partners, through the use of a wide area network, such as the Internet, are allowed unlimited electronic access to the product design as it proceeds. This is done by working with a compatible and integrated suite of engineering, design, planning and visualization tools used throughout the process.

Although each enterprise has unlimited access to the product database as it is developed, the project manager must also devise a scheme to ensure all team members are working with the same data set as the project progresses. To accomplish this task, the team members need to agree upon a central repository for the database and ensure that this central database is updated regularly.

Perhaps the most significant advantage to this model is that it is a vehicle for the owner, designer and shipyard to simultaneously participate in the process and consequently, the vessel design need only be done once. There is no need to draw a distinction between concept/contract design and detail design because all parties can collaborate throughout the design process. However, while the inefficiencies of the typical design process described earlier in this section can be greatly reduced or eliminated, care needs to be taken in balancing project risks and responsibilities. 


\section{CASE STUDY OF SME'S OPERATING IN AN EXTENDED ENTERPRISE ENVIRONMENT}

A key reason driving the development of extended enterprises by SMEs is the economics of obtaining services for completing a specific project, while avoiding the overhead of maintaining capabilities that can only be employed sporadically. Commercial boatbuilding offers an example of the development of such relationships.

In the Pacific Northwest region of the United States, a vibrant small boatbuilding industry exists. Typically, potential owners contact a boatbuilder concerning the project. These boatbuilders provide a facility primarily capable of assembling a boat from parts and components that are manufactured and purchased from outside the boatbuilders facility, and offering the opportunity to launch and test the completed boat. The core competencies and facilities offered are therefore assembly skills, for structure and outfit systems, system integration and testing skills, and launching and assembly facilities.

Substantial additional competencies are required to successfully complete the project. Among these are engineering capabilities and parts manufacturing capabilities. It is common to purchase existing equipment from outside manufacturers, including larger components such as main propulsion engines, gears, and generators, and smaller components, such as pumps, valves, windows, and light fixtures. These products are rarely redesigned for a specific new boatbuilding project. On the other hand, it is common to design the hull of a boat for a specific project. This impacts the capability of the boat to satisfy the owners needs, including requirements of speed, handling, cargo carrying capacity, and so forth. Thus, an important part of the success of the project is the hull design and construction.

At least two additional SMEs are typically employed for this later requirement. These are design agents and structural parts producers. In a typical boatbuilding project, the production of structure involves the following steps:

1. Contract design

2. Detail design

3. Lofting

4. Structural material processing

5. Structural material assembly.

Step one is performed by a designer or design firm working directly for the owner, sometimes in consultation with the boatbuilder. Steps two and three are performed by another design firm, typically under contract to the boatbuilder. In a small boatyard, two to five vessels per year are built. The overhead cost associated with maintaining detail design and lofting capability cannot be justified. Step four is commonly performed by an independent structural material processing service center. These SMEs have NC cutting capability, often using computer generated 
information transferred directly from a design agent. The cut structural parts are then delivered directly to the boatyard. Here again, the overhead of maintaining $\mathrm{NC}$ cutting capability in a small boatyard cannot be justified by the volume of work anticipated (Lane, 1996).

\section{BALANCING RISK/RESPONSIBILITY/REWARD IN THE DESIGN OF THE VIRTUAL ENTERPRISE}

This simple example of an extended enterprise, while extremely successful, is not without it's difficulties. Of primary concern is the handling of problems that may occur as a part of this arrangement.

The three primary partners, the design agent, the structural material processing service center, and the boatyard are relatively small businesses, each with limited resources. There is no obvious primary contractor, with smaller sub-contractors, as is the case with many extended enterprise arrangements. Thus there is no obvious primary responsibility for this part of the project.

The typical problems that have been encountered are in the following areas:

1. Information generation, by the design agent

2. Information exchange, between the design agent and the processing service center

3. Parts production, by the processing service center

4. Parts assembly, by the boatyard.

Contract design includes a lines plan, which defines the hull form. This information is used for critical design development, and is essential for performance prediction. However, contract lines plans are not in sufficient detail to be directly useable for lofting. Thus an additional detail definition, including the critical lines fairing activity, must be performed by the design agent in preparation for transferring data to the material processing service center. Additionally, the design agent must include internal structure, which is also not defined in detail by contract drawings. The design agent must consider the boatyard assembly practices, including welding techniques, assembly sequences, and weld distortion and shrinkage, in order to properly develop the information required by the material processing service center. Finally, consideration of the integration of the outfit systems with the structure must also take place at this time (Pollard, 1996).

Information transfer problems can occur due to difficulties in transmission facilities (busy or dirty telephone lines, etc.) and due to different software employed by the design agent and the material processing service center.

The material processing service center must control the accuracy of parts produced and the marking and packaging of the parts when shipped to the boatyard. Issues include efficient use of raw material, accuracy and clarity of marking, and control of shipments. 
The final step is the use of the parts by the boatyard. Included here is the accuracy of the assembly process, control, handling, and storage of material before and during use, and the general planning process employed by the boatyard.

In this environment, problem resolution becomes extremely important; however, since there is no single party responsible for managing these activities, it becomes very inefficient. All parties must become involved in assessing the cause of problems, identifying solutions, and recovering from their economic impact. Typically, problems generate costs in two areas, wasted material and schedule degradation. Naturally, additional time is required by some or all of the members of the extended enterprise, which also adds to the cost of the project. To date, problems have been solved by mutual agreement and by sharing of costs.

The requirement to share costs among the partners is counter productive to the goals of each enterprise. To implement an effective virtual enterprise that is not only geographically disbursed, but is set in a collaborative environment as well, several solutions are available. Technology, when appropriately applied, can aid the extended enterprises. In particular, statistical quality control offers the opportunity to minimize production problems at both the material processing service center and the boatyard; the use of 3D computer modeling and product model databases will help the planning and interchange of information between all three partners; and communications technologies can continue to be implemented as they improve. In addition to the application of technology, the inclusion of the project management function in the enterprise will ensure that its goals can be achieved.

\section{THE ROLE OF THE PROJECT MANAGER}

As described by the case study, the current state of the extended enterprise among SME's in the US marine industry is missing a means for a single organization to perform basic project management functions. As evidenced by inefficient problem solving in times of conflict, the function of project management is passed along from enterprise to enterprise in an ad hoc fashion. Often, after discovery of a problem, the enterprise bearing the highest degree of risk will assume the lead in reaching resolution to the conflict at hand. Although SME's have joined together for completion of a project, this environment inhibits the continuous alignment of the individual goals of the project partners.

The model of the virtual enterprise presented in Figure 2 provides that missing element. As described above, the SME's that make up the elements of the virtual enterprise have a strong, narrowly focused set of core competencies. The project manager provides a means for these SME's to concentrate on their tasks, while integrating those tasks and fostering effective communication between the individual enterprises. In a sense, the function of the Project Manager is analogous to a neutral file used to transfer data among different applications and platforms. 
The Project Management Institute (PMI) suggests nine skill areas in which the project manager must be proficient in order to successfully manage a project (PMI, 1996). These are:

1. Integration Management.

2. Scope Management.

3. Time Management.

4. Cost Management.

5. Quality Management.

6. Human Resource Management.

7. Communications Management.

8. Risk Management.

9. Procurement (Contracts) Management.

The project manager must possess a wide body of knowledge; however, in possessing this knowledge, his core competence is that of project management. In addition to possessing a broad range of management skills, the project manager must also maintain a domain specific expertise, as suggested by integration management at the top of this list. For example, in the marine industry, he must have a general knowledge of vessel requirements and performance specifications, equipment and components of which the vessel is comprised and vendors and suppliers that can provide the required products and services.

\section{CONCLUSIONS}

Great strides have been made toward collaborative engineering in a distributed, collaborative environment. Initially, the concept of concurrent engineering allowed corporations to make significant productivity gains through a methodology that allowed for functional tasks to be accomplished in parallel. While product development cycle time was substantially reduced, a truly collaborative engineering environment did not exist unless team members were co-located.

Advances in communications technology has enabled the formation of the extended enterprise, allowing SME's to stay focused on their core competencies, while banding together to complete projects that none would be able to accomplish individually. In theory, the extended enterprise has empowered SME's to create collaborative environments while remaining geographically dispersed. However, in practice SME's engaged in a virtual extended enterprise can lose sight of the project goals and become entangled in resolving conflicts among themselves. This is evidenced by the case study presented in this paper. While the three project partners accomplished the set of five tasks, there was no single entity to take responsibility for mediating communication and resolving the conflicts between them.

To continue the evolution of the virtual extended enterprise and ensure that it can indeed create a collaborative environment among its partners, the authors have 
presented a model for the US marine industry in Figure 2. In this model the project manager figures prominently. The project manager is the logical choice to take responsibility for the successful management of the project. As the enterprise partners have strength in their areas of expertise, so must the project manager. He must be competent in all areas of project management, and possess a broad knowledge of the domain in which he is functioning.

\section{REFERENCES}

Caskey, K. R. (1995), Co-operative Distributed Simulation and Optimisation in Extended Enterprises, Presented at IFIP Conference, Seattle, WA, USA.

Kelly, K. (Jun. 1996), 'The Economics of Ideas', Wired.

Lane, K. Interview with R. L. Storch, June, 1996.

Pels, ir. H.J. (1995), Control of CE-Process by Document Quality Levels, Presented at IFIP Conference, Seattle, WA, USA.

Pollard, S., Barry, C., et.al. (Jan. 1996), 'Loftsman's Liability', Professional Boat Builder.

Project Management Standards Committee, PMI, (1996), A Guide to the Project Management Body of Knowledge, Project Management Institute, Upper Darby, PA.

\section{BIOGRAPHY}

Matt Williamson is the owner of Project Solutions, a project management consulting firm in Seattle, Washington. He holds a BSME from the University of Utah and a MBA in Engineering and Technology Management from City University. He has worked in the marine industry for thirteen years, most recently developing business processes for the Extended Enterprise. He is a member of PMI, ASME, SNAME, IFIP WG 5.7 and the NSRP.

Richard Lee Storch is an Associate Professor of Industrial Engineering at the University of Washington. He holds a Ph.D. from the University of Washington, a Master's from M.I.T., and a Bachelor's from Webb Institute of Naval Architecture. His research has concentrated on productivity and quality improvement in ship production and large assembly manufacturing systems. He is a member of the Ship Production Committee, SNAME, IFIP WG 5.7, IIE, ASNE, and SME, and is the lead author of the text Ship Production. 